\title{
CHAETOGYNE ZOAE SP. NOV. (DIPTERA, TACHINIDAE)
}

\section{Ronaldo Toma ${ }^{1}$}

\begin{abstract}
CHAETOGYNE ZOAE SP. NOV. (DIPTERA, TACHINIDAE). A third new species of Chaetogyne Brauer \& Bergenstamm, 1889 is described from Brazil (Paraná, Santa Catarina, Rio Grande do Sul) and a key for the three species of this genus is presented.
\end{abstract}

KEYWORDS. Chaetogyne, Theresiini, Tachinidae, Taxonomy, Neotropical.

\section{INTRODUÇÃO}

BRAUER \& Bergenstamm (1889) propuseram o gênero monotípico Chaetogyne para a espécie Stomoxys vexans Wiedemann, 1830. CuRRAN (1937) descreveu a segunda espécie do gênero, Chaetogyne analis. Esse gênero é neotropical e, segundo o catálogo de Guimarães (1971), está arrolado na tribo Theresiini.

A espécie nova aqui descrita, Chaetogyne zoae, compartilha as seguintes características com C. vexans e C. analis: carena facial proeminente, em geral, com um sulco na extremidade superior; probóscide longa, fina, e cerca de uma vez e meia o comprimento da cabeça; pedicelo com uma cerda longa, ultrapassando a metade do comprimento da arista; esta plumosa com a base levemente espessa; triângulo ocelar piloso; parafrontália com pêlos; margem subvibrissal com cerca de quatro cerdas, em geral, contínuas às cerdas da margem subcranial; prosterno glabro; esternopleurais com pêlos finos e longos, subjacentes à fileira de cerdas esternopleurais; margem posterior da coxa posterior nua.

Lista de acrônimos: MZSP, Museu de Zoologia, Universidade de São Paulo; MCTP, Museu de Ciências e Tecnologia, Pontifícia Universidade Católica do Rio Grande do Sul.

Chave para as espécies de Chaetogyne

1. Abdome quase tão largo quanto longo; tergito 3, nos machos, sem cerdas marginais medianas C. vexans (Wiedemann)

Abdome pouco mais longo do que largo (fig. 1); tergito $3 \mathrm{com}$ um par de cerdas marginais medianas

2. Abdome castanho-escuro com densa pruinosidade cinza nos tergitos 5 e 6 e na superfície dorsal da terminália C. analis Curran

Abdome alaranjado com forte pruinosidade amarelo-dourada e com uma mancha preta triangular direcionada para trás no sintergito $1+2$ e tergito 3 ..... C. zoae sp. nov.

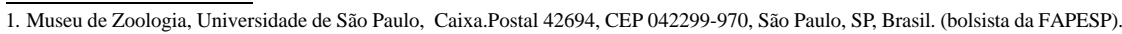




\section{Chaetogyne zoae sp. nov.}

(Figs. 1-4, 6-9)

Diagnose. Caracteriza-se pela calíptera relativamente mais clara; pelo escutelo alaranjado; pelo abdome alaranjado com uma mancha preta triangular direcionada para trás no sintergito $1+2$ e tergito 3 , e com forte pruinosidade amarelo-dourada.

Macho. Comprimento, 11-13 mm. Cabeça (fig. 2) pardo-amarelada com pruinosidade cinza-amarelada. Vértice cerca de 0,20 da largura da cabeça. Fronte castanho-escura, alargando-se em direção à base antenal. Parafrontália mais larga em direção à pró-fronte; esta situada pouco abaixo da metade da altura do olho. Parafaciália com largura constante ao longo de sua extensão, cerca da mesma largura da pró-fronte. Antenas alaranjadas, separadas pela carena facial; flagelômero cerca do dobro do comprimento do pedicelo. Palpos alaranjados e relativamente curtos. Cerdas ocelares longas, maiores ou iguais ao comprimento das cerdas verticais internas. Cerdas frontais 14-16, longas, estendendo-se até a margem superior do pedicelo, as mais próximas das extremidades superior e inferior menores. Parafrontália com pêlos adjacentes à fileira de cerdas frontais. Parafaciália e pró-fronte glabras. Faciália com duas ou três cerdas pouco maiores que o terço do comprimento da vibrissa, estendendo-se 0,20 da distância da vibrissa à base da antena. Gena cerca de 0,40 da altura do olho.

Tórax castanho com pruinosidade cinza-amarelada; escutelo em geral mais claro. Proepisterno piloso. Catepisterno com três cerdas, formando um triângulo. Pós-pronoto em geral com cinco cerdas: três cerdas basais mais ou menos alinhadas, com a cerda basal mediana menor e mais próximo da cerda basal externa do que da cerda basal interna; cerda anterior externa posicionada mais ou menos em frente da basal mediana; cerda anterior interna situada mais anteriormente, quase alinhada com as cerdas anterior e basal externas. Acrosticais 2:4, com as três primeiras pós-suturais relativamente curtas. Dorsocentrais 3:4, com a segunda pós-sutural em geral reduzida. Escutelo com três pares de cerdas longas: um par de basais, um de laterais e um par de apicais convergentes; três ou quatro cerdas discais margeando o escutelo. Pernas castanhas; garras tarsais relativamente curtas, cerca de dois terços do comprimento do último tarsômero. Asa hialina, levemente alaranjada próximo à base; veia $\mathrm{M}$ com curvatura angulosa, e terminando separada de $\mathrm{R}_{4+5}$; Célula $\mathrm{r}_{4+5}$ terminando antes do ápice da asa; calípteras com pruinosidade marrom e margem amarela.

Abdome (fig. 1) alaranjado com forte pruinosidade amarelo-dourada; uma mancha triangular preta direcionada para trás, em geral, no sintergito $1+2$ e tergito 3 ; este com um par de cerdas marginais medianas e tergitos 4 e 5 com uma fileira de cerdas marginais medianas longas e espessas, as do tergito 5 relativamente mais fracas.

Terminália. Esternito 5 em geral pouco mais largo do que longo (fig. 9). Hipândrio com a estrutura de ligação com o gonópodo relativamente alongada e esclerotinizada (fig. 8). Parâmeros fusionados na porção dorsal, em forma de quilha. Edeago basalmente fusionado com o parâmero; porção basal posterior com uma placa esclerotinizada; porção basal anterior membranosa e microdenteada, de onde parte uma estrutura cilíndrica, alongada, também membranosa e com microdenteações menores (figs. 6, 7). Cercos e surstilos, vista posterior (fig. 4), aqueles mais alargados basalmente, estreitando-se do meio para o ápice; surstilos robustos, estreitando-se em direção ao ápice, região externa mais convexa. Cercos, em vista lateral (fig. 3), com a metade apical curvada para trás, 

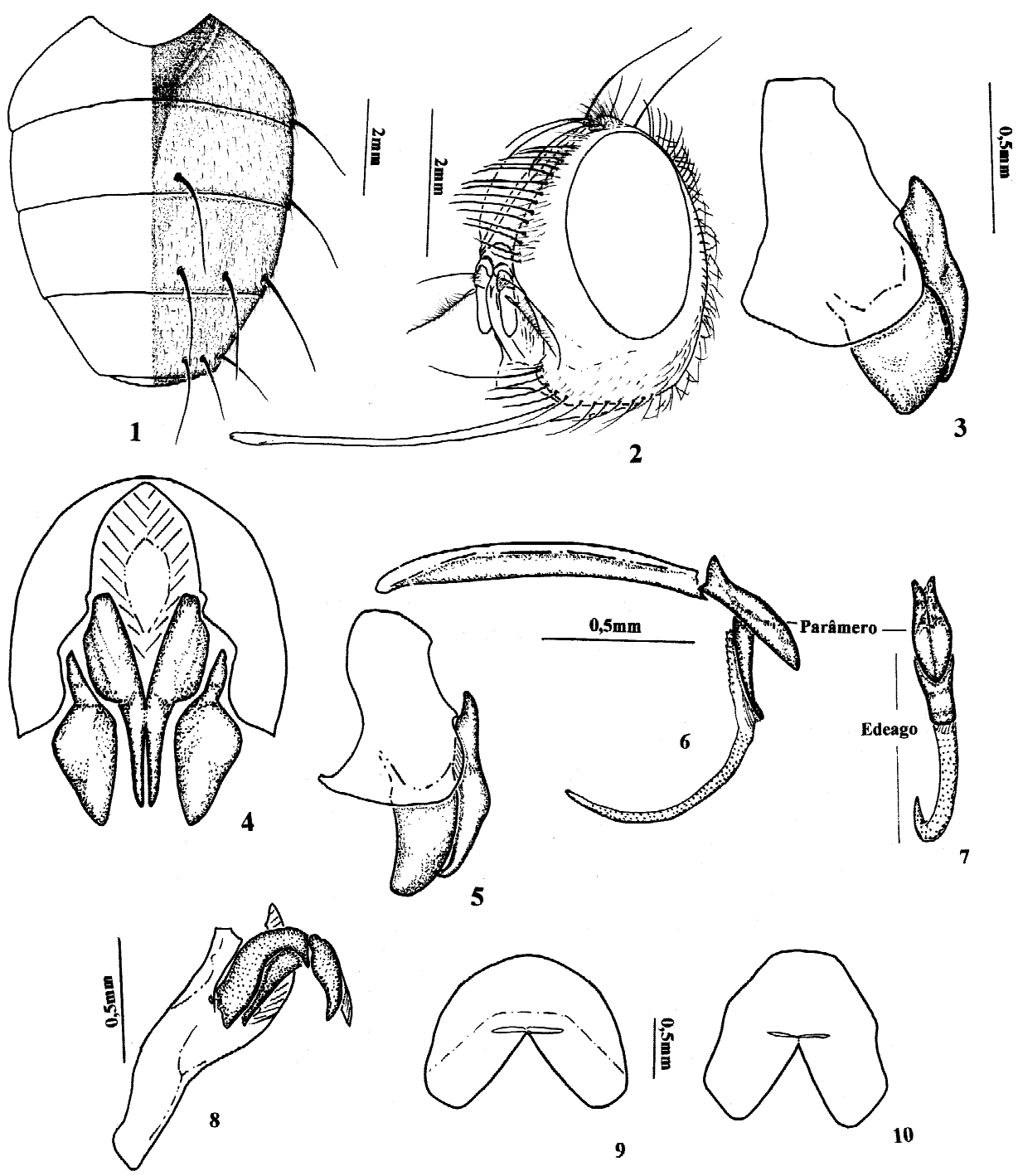

Figs. 1-10. Chaetogyne zoae sp. nov. (São Francisco de Paula, RS, 12.II.1998): 1, abdome, vista dorsal; 2, cabeça, vista látero-frontal; 3 , cercos e surstilos, vista lateral; 4, vista posterior. C. vexans Wiedemann: 5, cercos e surstilos, vista lateral. C. zoae: 6, apodema do edeago, parâmero e edeago, vista lateral; 7, edeago, vista posterior; 8, hipândrio, vista látero-ventral; 9, esternito 5. C. analis Curran: 10, esternito 5. 
ápice levemente curvado para frente; surstilos robustos e subtriangulares, porções posterior e anterior levemente convexas, a porção posterior um pouco menos.

Distribuição geográfica. Brasil: Paraná, Santa Catarina e Rio Grande do Sul.

Comentário. As identificações conferem completamente, no caso de Chaetogyne vexans, com a resdescrição de AldRICH (1925) e, de C. analis, com a descrição original de Curran (1937). C. zoae (fig. 3) difere de C. vexans (fig. 5) pela porção apical dos cercos relativamente menos curvada para frente e pela região anterior dos surstilos levemente convexa; difere de $C$. analis (fig. 10) pelo esternito 5 em geral pouco mais longo do que largo (fig. 9).

Etimologia. Esta espécie foi descrita em homenagem à minha esposa Zoraida Fernández.

Material-tipo. Holótipo o', BRASIL, Santa Catarina, Rio das Antas, I.1953, Camargo col. (MZSP). Parátipos: Paraná, ơ, XI.1946, Mallet \& L. Travassos Filho col. (MZSP); Curitiba, ơ, P. Machado col. (MZSP); Santa Catarina: Rio das Antas, $4 \sigma^{\top}$, I.1953, Camargo \& Dente col. (MZSP); idem, $60^{\circ}$, Camargo \& Andreatta col. (MZSP); idem, 20 o', Camargo col. (MZSP); Rio Grande do Sul, São Francisco de Paula, 2 o', 27.I. e 12.II.1998, Koehler col. (MCTP).

\section{REFERÊNCIAS BIBLIOGRÁFICAS}

AlDRich, J. M. 1925. Notes on some types of American Muscoid Diptera in the collection of the Vienna Natural History Museum (cont.). Ann. ent. Soc. Am., Columbus, 18: 107-130.

Brauer, F. \& Bergenstamm, J. E. Von. 1889. Die Zweiflügler des Kaiserlichen Museums zu Wien. IV. Vorarbeiten zu einer Monographie der Muscaria Schizometopa (exklusiv Anthomyidae). Pars I. Denkschr. Akad. Wiss., Wien, 56: 69-180.

Curran, C. H. 1937. Three new Neotropical Diptera. Revta Chilena Hist. Nat., Santiago, 40: 331-335.

Guimarães, J. H. 1971. Family Tachinidae. In: PAPAVERO, N. ed. A catalogue of the Diptera of the Americas South of the United States. São Paulo, Universidade de São Paulo. v. 104, 333p.

WiEDEMANN, C. R. W. 1830. Aussereuropäische zweiflügelige Insekten. Hamm, Schulzischen Buchhandlung. v. 2,684 p.

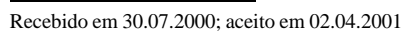

